\title{
Testing the proficiency to distinguish locations with elevated plantar pressure within and between professional groups of foot therapists
}

\author{
Nick A Guldemond* ${ }^{*}$, Pieter Leffers ${ }^{\dagger 2}$, Fred HM Nieman ${ }^{\dagger 3}$, Antal P Sanders ${ }^{4}$, \\ Nicolaas C Schaper ${ }^{5}$ and Geert HIM Walenkamp ${ }^{\dagger 1}$
}

Address: ${ }^{1}$ Orthopaedic Surgery, University Hospital Maastricht, P.O. Box 5800, 6202 AZ, Maastricht, The Netherlands, ${ }^{2}$ Epidemiology, Faculty of Medicine, Maastricht University, P.O. Box 616, 6200 MD, Maastricht, The Netherlands, ${ }^{3}$ Clinical Epidemiology and Medical Technology Assessment, University Hospital Maastricht, P.O. Box 5800, 6202 AZ, Maastricht, The Netherlands, ${ }^{4}$ Rehabilitation Medicine, University Hospital Maastricht, P.O. Box 5800, 6202 AZ, Maastricht, The Netherlands and 5 Internal Medicine, University Hospital Maastricht, P.O. Box 5800, 6202 AZ, Maastricht, The Netherlands

Email: Nick A Guldemond* - ngu@orthop.unimaas.nl; Pieter Leffers - p.leffers@epid.unimaas.nl; Fred HM Nieman - fni@oazg.azm.nl; Antal P Sanders - asan@rev.azm.nl; Nicolaas C Schaper - nsc@sint.azm.nl; Geert HIM Walenkamp - gwa@sort.azm.nl

* Corresponding author †Equal contributors

Published: 0 I December 2006

BMC Musculoskeletal Disorders 2006, 7:93 doi:10.1 186/147/-2474-7-93
Received: 18 March 2006

Accepted: 0I December 2006

This article is available from: http://www.biomedcentral.com/I47I-2474/7/93

(C) 2006 Guldemond et al; licensee BioMed Central Ltd.

This is an Open Access article distributed under the terms of the Creative Commons Attribution License (http://creativecommons.org/licenses/by/2.0), which permits unrestricted use, distribution, and reproduction in any medium, provided the original work is properly cited.

\begin{abstract}
Background: Identification of locations with elevated plantar pressures is important in daily foot care for patients with rheumatoid arthritis, metatarsalgia and diabetes. The purpose of the present study was to evaluate the proficiency of podiatrists, pedorthists and orthotists, to distinguish locations with elevated plantar pressure in patients with metatarsalgia.
\end{abstract}

Methods: Ten podiatrists, ten pedorthists and ten orthotists working in The Netherlands were asked to identify locations with excessively high plantar pressure in three patients with forefoot complaints. Therapists were instructed to examine the patients according to the methods used in their everyday clinical practice. Regions could be marked through hatching an illustration of a plantar aspect. A pressure sensitive platform was used to quantify the dynamic bare foot plantar pressures and was considered as 'Gold Standard' (GS). A pressure higher than $700 \mathrm{kPa}$ was used as cut-off criterion for categorizing peak pressure into elevated or non-elevated pressure. This was done for both patient's feet and six separate forefoot regions: big toe and metatarsal one to five. Data were analysed by a mixed-model ANOVA and Generalizability Theory.

Results: The proportions elevated/non-elevated pressure regions, based on clinical ratings of the therapists, show important discrepancies with the criterion values obtained through quantitative plantar pressure measurement. In general, plantar pressures in the big toe region were underrated and those in the metatarsal regions were overrated. The estimated method agreement on clinical judgement of plantar pressures with the GS was below an acceptable level: i.e. all intraclass correlation coefficient's equal or smaller than .60. The interobserver agreement for each discipline demonstrated worrisome results: all below .18. The estimated mutual agreements showed that there was virtually no mutual agreement between the professional groups studied.

Conclusion: Identification of elevated plantar pressure through clinical evaluation is difficult, insufficient and may be potentially harmful. The process of clinical plantar pressure screening has to be re-evaluated. The results of this study point towards the merit of quantitative plantar pressure measurement for clinical practice. 


\section{Background}

Elevated plantar peak pressures are associated with a wide variety of foot impairments like rheumatoid arthritis, metatarsalgia and diabetes. Reduction or off-loading of plantar tissue stress is a commonly therapeutical concept for these conditions. Off-loading strategies could include padding and strapping therapy, foot orthoses, therapeutic footwear or total contact casts [1,2]. Identification of locations with elevated plantar pressures seems to be logical requisite for effective off-loading [1-7]. Information about locations with elevated plantar pressure can be obtained through physical examination and is based on e.g. callus formation, blisters, soft tissue quality, painful regions and deformities. Various techniques such as footprints and podoscopes are used to measure static and dynamic plantar pressure patterns [8-12]. Advanced pressure sensitive devices i.e. platforms and in-shoe devises, provide information about the location as well as the magnitude of plantar peak pressure $[1,5]$. In The Netherlands this electronic equipment is sparsely used in clinical settings and the aforementioned traditional techniques are yet essential tools for daily practice.

In The Netherlands, allied foot care is provided by podiatrists, pedorthists (orthopaedic shoe technicians) and orthotists (orthopaedic technicians) [13-15]. Pedorthists are specialized in foot orthosis therapy for orthopaedic shoe wear, whereas podiatrists and orthotists mainly provide foot orthoses for non-orthopaedic shoe wear. In general, orthotists take care of more severe disorders than podiatrists. Although each discipline has a specific focus on particular foot problems, all three disciplines use physical examination and footprints for identification of locations with elevated plantar pressure. In literature, peak pressure values similar or higher than $700 \mathrm{kPa}$ are frequently considered as abnormal or elevated [16-23]. On the contrary, studies in healthy subjects show that peak pressures were significantly lower than $700 \mathrm{kPa}$ [24-29].

The purpose of the present study was to evaluate the proficiency of podiatrists, pedorthists and orthotists, to distinguish locations with relatively elevated plantar pressures in patients with metatarsalgia.

\section{Methods \\ Therapists}

As representatives of their professional groups, ten podiatrists, ten pedorthists and ten orthotists from the southern part of The Netherlands were asked to construct foot orthoses for three patients with metatarsalgia[15]. Podiatrists were approached through telephone directories. Companies of pedorthists and orthotic workshops were approached through member lists of the professional associations. Each delegated between one and three therapists for the study. The median professional experience in years (range) was 7.5 (14), 16.5 (34) and 20 (30) respectively for podiatrists, pedorthists and orthotists.

\section{Patients}

Three patients with metatarsalgia: 2 females of 60 and 61 years old and a 37 years old male, with fore foot complaints and elevated plantar peak pressures were selected from an orthopaedic outpatient clinic. The male patient had foot problems related to psoriatic arthritis. Additional details about the patients are given in table 1. Before the start of the study, patients were informed about all study procedures and their possible risks. The Research Ethical Committee of the University Hospital Maastricht approved the study.

\section{Procedure}

A central session was organised at the University Hospital Maastricht where the therapists could perform their physical examination for each patient. Therapists were asked to identify locations with elevated plantar pressure, which could be marked through hatching an illustration of a plantar aspect (figure 1). Therapists were instructed to examine the patients according to the methods used in their everyday clinical practice. An EMED SF- $4^{\circledast}$ pressure platform (Novel, Munich) was used to quantify the bare foot plantar pressures of the patient's feet and was performed according to a two-step protocol [30-34]. This measurement was considered as 'Gold Standard' (GS). Bare foot peak pressures were estimated per foot, by calculating the mean over the readings of 5 consecutive measurements. This was done for six discrete regions: big toe (BT) and metatarsal one (mt-1) to five (mt-5), demarcated by Novel 'create any mask ${ }^{\circledR 1}$ software and verified through anterior-posterior radiographs[35].

\section{Statistical analysis}

Data were analysed by a mixed-model ANOVA and Generalizability Theory[36]. The GS plantar peak pressure was categorized into two classes: 'non-elevated' i.e. less or equal to $700 \mathrm{kPa}$ and 'elevated' i.e. more than $700 \mathrm{kPa}$. The six-factor ANOVA design was defined as 'Region by Side within Patient' by 'Therapist within Group' by 'Method'. Region is a fixed factor with six levels: big toe and mt-1 to mt-5. Side is fixed with two levels: left or right foot. Both factors are nested within Patient, which can be seen as a random factor with three levels: subject A, B and C. Therapist is a random factor with ten levels, nested within Group, a fixed factor with the three levels of discipline: podiatrists, pedorthists and orthotists. Finally, Method is a fixed factor with two levels: proportions elevated/non-elevated pressure as rated by the therapists and proportions according to the GS. Proportions of relatively elevated plantar pressure, F-ratios with degrees of freedom and pvalues belonging to the fixed part of the model, are computed with the computer program GENOVA[37]. 
Table I: Patient characteristics

\begin{tabular}{|c|c|c|c|c|c|c|}
\hline Patient & \multicolumn{2}{|c|}{$\mathbf{A}$} & \multicolumn{2}{|c|}{ B } & \multicolumn{2}{|c|}{ C } \\
\hline Gender & \multicolumn{2}{|c|}{ female } & \multicolumn{2}{|c|}{ Female } & \multicolumn{2}{|c|}{ male } \\
\hline Age (yr) & \multicolumn{2}{|c|}{60} & \multicolumn{2}{|c|}{61} & \multicolumn{2}{|c|}{37} \\
\hline Weight (kg) & \multicolumn{2}{|c|}{105} & \multicolumn{2}{|c|}{73} & \multicolumn{2}{|c|}{82} \\
\hline Body length (cm) & \multicolumn{2}{|c|}{178} & \multicolumn{2}{|c|}{154} & \multirow{2}{*}{\multicolumn{2}{|c|}{$\begin{array}{c}181 \\
\text { Arthritis psoriatica }\end{array}$}} \\
\hline \multirow[t]{2}{*}{ Systemic diseases } & \multirow[b]{2}{*}{ left } & \multirow[b]{2}{*}{ right } & \multirow[b]{2}{*}{ left } & \multirow[b]{2}{*}{ right } & & \\
\hline & & & & & left & right \\
\hline \multicolumn{7}{|l|}{$\begin{array}{r}\text { Structural } \\
\text { classification }\end{array}$} \\
\hline pes plano valgus & $\mathbf{x}$ & $\mathbf{x}$ & & & & \\
\hline calcaneus valgus & & & & & $\mathbf{x}$ & $\mathbf{x}$ \\
\hline hallux valgus & & & $\mathbf{x}$ & $\mathbf{x}$ & & \\
\hline bunion & & & $x$ & $\mathbf{x}$ & & \\
\hline claw toes & & & & & $\mathbf{x}$ & $\mathbf{x}$ \\
\hline \multicolumn{7}{|l|}{$\begin{array}{r}\text { Specific } \\
\text { diagnosis }\end{array}$} \\
\hline Metatarsalgia & $\mathbf{x}$ & $\mathbf{x}$ & $\mathbf{x}$ & $\mathbf{x}$ & $\mathbf{x}$ & $\mathbf{x}$ \\
\hline Plantar fasciitis & & $\mathbf{x}$ & & & & \\
\hline $\begin{array}{l}\text { MTP-I joint } \\
\text { Extension }\end{array}$ & $50^{\circ}$ & $50^{\circ}$ & $50^{\circ}$ & $35^{\circ}$ & $55^{\circ}$ & $60^{\circ}$ \\
\hline $\begin{array}{l}\text { MTP-I joint } \\
\text { Flexion }\end{array}$ & $45^{\circ}$ & $40^{\circ}$ & $30^{\circ}$ & $35^{\circ}$ & $40^{\circ}$ & $45^{\circ}$ \\
\hline
\end{tabular}

$\mathrm{Yr}=$ years, $\mathrm{kg}=$ kilogram, $\mathrm{cm}=$ centimetre, $\mathrm{MTP}=$ metatarsophalangeal

Variance components are also estimated by this program and method agreement was calculated according to the principles of Streiner \& Norman[38]. Decision analysis used in Generalizability Theory resulted in the estimated method agreement with the categorized GS of a randomly chosen therapist (out of 10 per group). The agreement among therapist and the mutual agreement between disciplines was also calculated. This method agreement can be interpreted as a multivariate Intraclass Correlation Coefficient (ICC) as well as a multivariate Kappa[39,40]. Results can be between '0' i.e.: no method agreement at all and '1' i.e.: perfect method agreement. A method agreement of 0.80 is defined as acceptable[40]. Throughout the text, a p-value of less than 0.05 is considered statistically significant.

\section{Results}

The frequency distribution of regions with excessively high pressure, as rated by the therapists, against the plantar pressure measured with the pressure platform (GS) are presented per discipline in figures 2 to 4 . Table 1 presents the background characteristics of the patients included in the study. Table 2 provides the pressure platform (GS) dynamic bare foot peak pressure measurements (in $\mathrm{kPa}$ ) for each of the six forefoot regions and for both feet in each patient. High plantar pressure measurements (>700 kPa) have been marked with boxes.
The observed proportions of elevated plantar pressure according to the GS and to the ratings per discipline, averaged over three patients (both feet and all six regions) are presented in Table 3. The differences in proportions of elevated plantar pressures between the GS and the ratings per discipline show significant discrepancies (all p-values < $.05)$. On the average, one can see an underestimation in the big toe region and an overestimation in the other regions when compared to the GS. The standard deviations indicate large variations around the point estimate. For example, the proportion of elevated plantar pressure per location according to the GS is determined by the number of regions with observed elevated pressure to all regions for that location: for $\mathrm{BT}$, three of the six regions (three patients both feet) had elevated pressure i.e. 3:6 = 0.50 . The proportion for BT based on ratings by the three disciplines was 0.36, indicating an underestimation. Regions with elevated plantar pressure were frequently underrated: $35 \%$ of the podiatrists, $45 \%$ of the pedorthists and $53 \%$ orthotists, did not indicate the pertaining regions as having high pressure, i.e. they scored falsely negative. Ratings of orthotists for high pressure under the BT were illustrative: right side of figure 4 .

Table 4 presents the estimated within-groups method agreement ICCs between GS and ratings. This ICC is calculated for each of the three disciplines and for each of the six forefoot regions, i.e. taking into account variance 


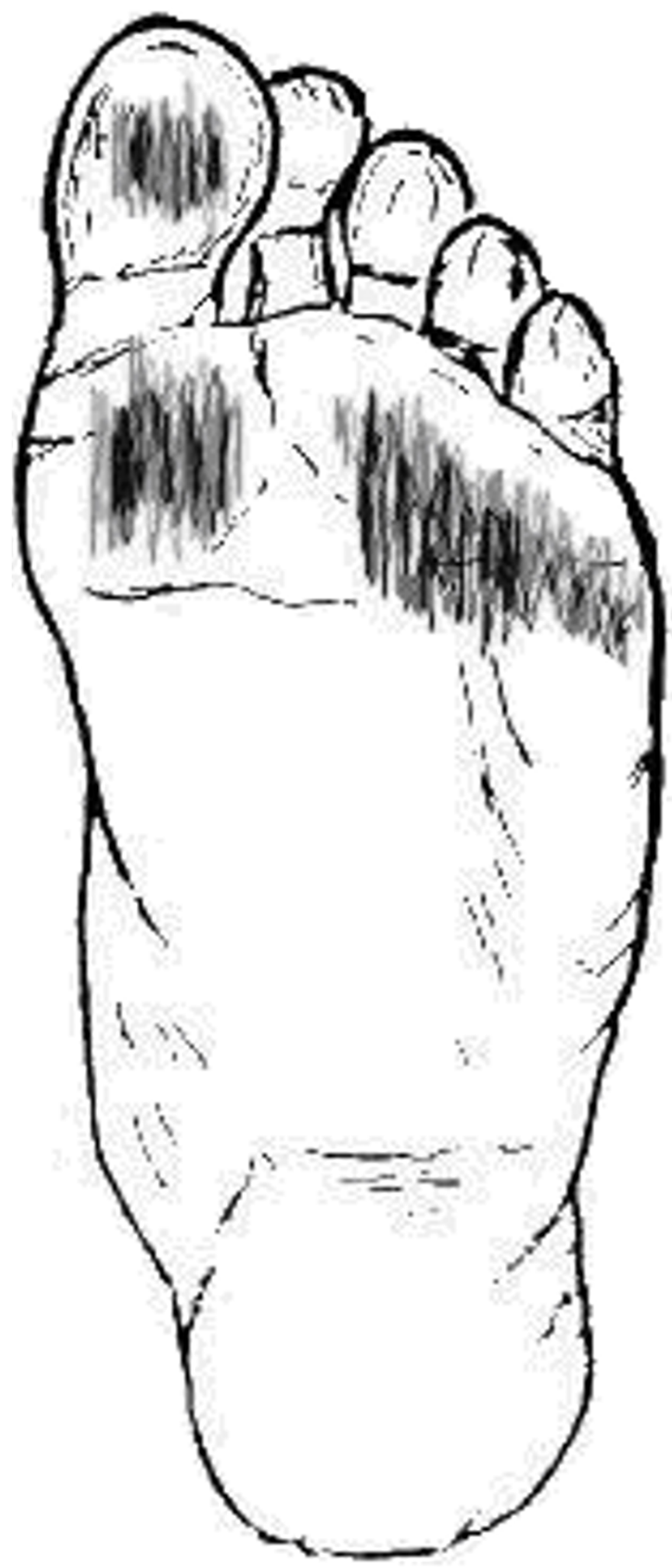

Figure I

Marking of regions with elevated plantar pressure. Presumed regions with elevated plantar pressure are marked through hatching an illustration of a plantar aspect. 


\section{Ratings by podiatrists \& plantar pressure according to GS}

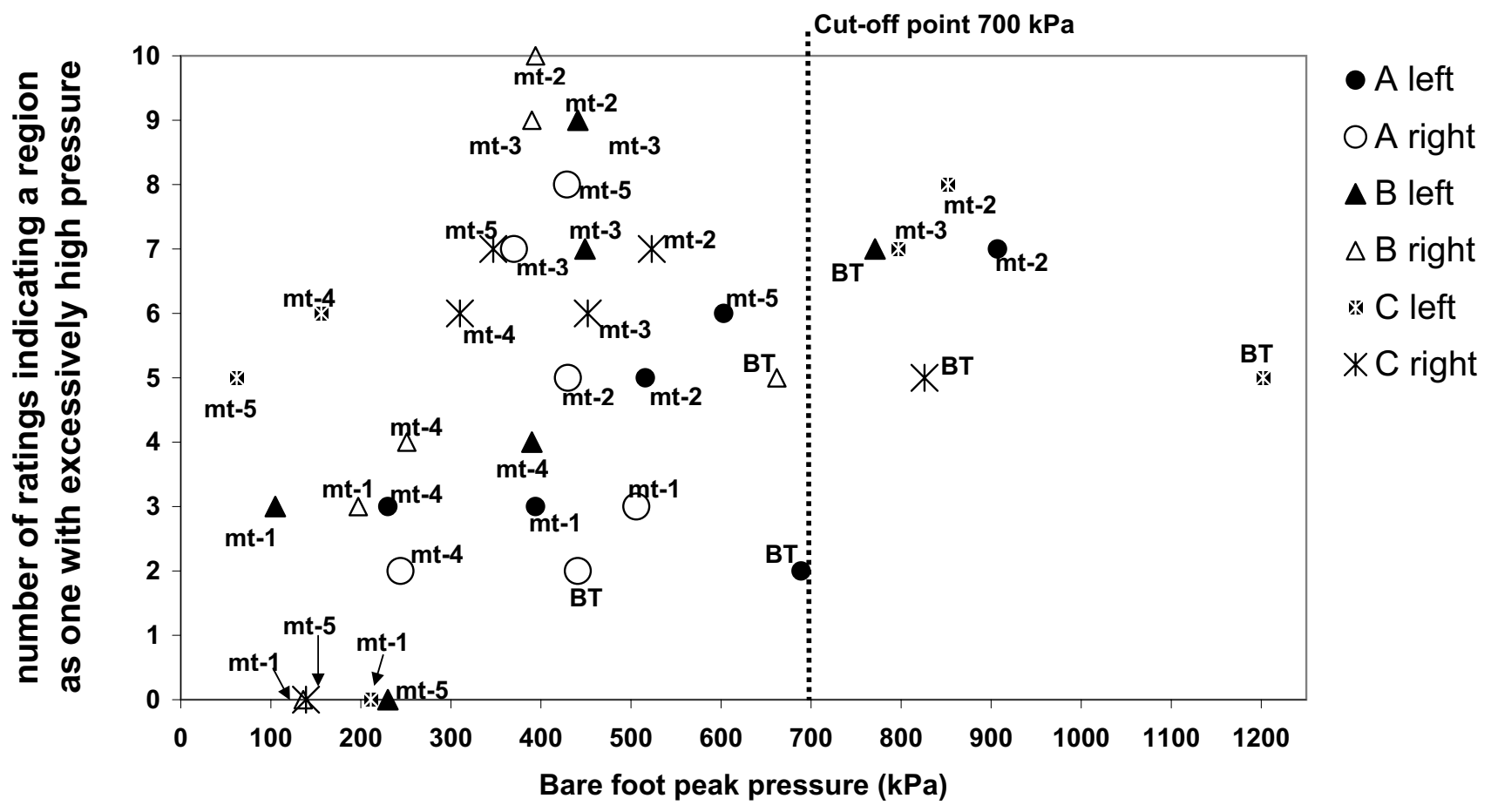

Figure 2

Ratings by podiatrists. The distribution of ratings of podiatrists who indicated a region as one with excessively high pressure, against the plantar pressure measured with the pressure platform (Gold Standard).

between therapists and variance between ratings and GS, see appendix formula A1. The mechanism of this comprehensive measure of agreement can be clarified by table 5 , where the components of variance used for the BT region per discipline are presented. Part A of table 5 is the numerator of formula $\mathrm{A} 1$, whereas part $\mathrm{B}$ contains the relevant variance components of the denominator. The ICC is calculated through $\mathrm{A}_{\text {total }} /\left(\mathrm{A}_{\text {total }}+\mathrm{B}_{\text {total }}\right)$. For the BT region, one can see that orthotists disagree more with the GS than podiatrists and pedorthists (see the overall prevalence proportions in table 3 ). However, the ICC for the orthotist method agreement is somewhat higher (0.86) than the ones for podiatrists (0.77) and pedorthists (0.77).

The $P_{\text {atient }} \times \mathbf{M}_{\text {ethod }}$ component which accounts for the variance between clinical judgment and GS, is for orthotists relatively large (34\%) compared to the ones for podiatrists $(15 \%)$ and pedorthists $(20 \%)$, see also table 3 . The within group variance, $P_{\text {atient }} \times T_{\text {herapist }}$ component, for orthotists is relatively small (3\%) showing good interobserver agreement compared to the within group variance of podiatrists $(14 \%)$ and pedorthists $(9 \%)$, table 5 . This explains why the orthotist ICC is large despite the GS differences on overall prevalence proportion. However, when the inter-observer agreement is calculated over all regions and the $\mathbf{P}_{\text {atient }} \times \mathbf{M}_{\text {ethod }}$ component is excluded (formula A5), then the ICCs result in: 0.18 for orthotists, 0.13 for podiatrists and 0.04 for pedorthists.

The estimated method agreement (ICC) per discipline, is $0.67,0.65$ and 0.76 for podiatrists, pedorthists and orthotists respectively (table 4). These ICCs are averaged over both feet and over all regions: formula A3. The overall method agreement, calculated through formula A4, turns out to be 0.70 . All these results are below the critical level for sufficient agreement (0.80) and it appears that there is no discipline superior to another. Regions in which an acceptable level of estimated method agreement with GS is reached are BT and $\mathrm{mt}-2$, respectively 0.80 and 0.82 : formula A2.

Table 6 shows the estimated mutual method agreement (ICC) between the three disciplines. The ICC in this table can be interpreted as a generalized multivariate kappa between ratings of two professional groups. Most of the estimated mutual agreement ICCs for the separate regions 


\section{Ratings by pedorthists \& plantar pressure according to GS}

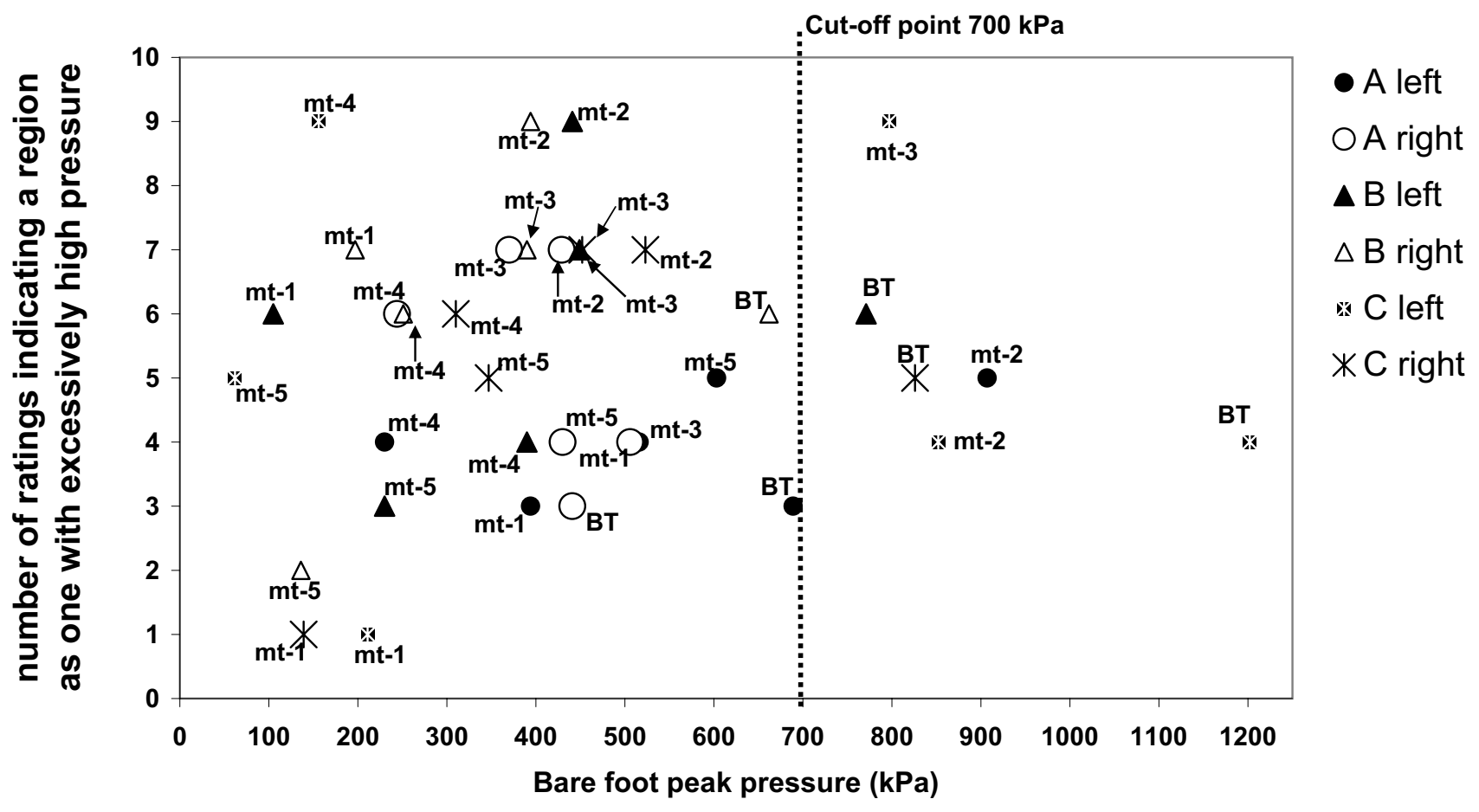

Figure 3

Ratings by pedorthists. The distribution of ratings of pedorthists who indicated a region as one with excessively high pressure, against the plantar pressure measured with the pressure platform (Gold Standard).

are below 0.50 (formula B1), which indicates that there was a low mutual agreement among therapists from different disciplines. Whereas, the mutual method agreement averaged over regions, calculated through formula B2, showed virtually no agreement.

\section{Discussion}

We examined three professional groups of foot care specialist regarding their ability to identify locations with elevated plantar pressures. The proportions based on clinical ratings of the therapists, show rather worrisome dissimilarities with the criterion values obtained trough quantitative plantar pressure measurement (GS). On the average, plantar pressures in the big toe region were underestimated and those in the metatarsal regions were overestimated. The estimated method agreement of clinical judgement of plantar pressures with the GS was below a predominated acceptable level. This generalized measure of agreement takes into various sources of variation. If one solely look to the agreement among therapists, then the results are fairly poor. The estimated mutual agreements showed that there was a low mutual agreement between the professional groups studied, indicating a large variability between disciplines. The problem of professional variability for other aspects of foot care was shown in a previous report [15].

There is some discussion about the level of agreement for medical diagnosis by professionals in day-by-day care. We considered that identification of locations with elevated pressures is an important aspect in foot care decisionmaking. For example, in the diabetic foot accurate identification is essential to define the treatment for prevention of (re)ulceration. Over- and underestimating plantar pressure, i.e. false positive and false negative ratings respectively, may lead to neglect of harmful elevated pressures. False negative means that a region was indicated as one without excessively high pressure, while the actual peak pressure was above the criterion level i.e.: $700 \mathrm{kPa}$ and vice versa for false positive. Off-loading strategies in e.g. foot orthoses therapy, is achieved by shifting the excessive load to adjacent areas[41]. As a consequence, the actual 'risk region' could be exposed to a higher load and this could be disastrous for patients with insensate feet. 


\section{Ratings by orthotists \& plantar pressure according to GS}

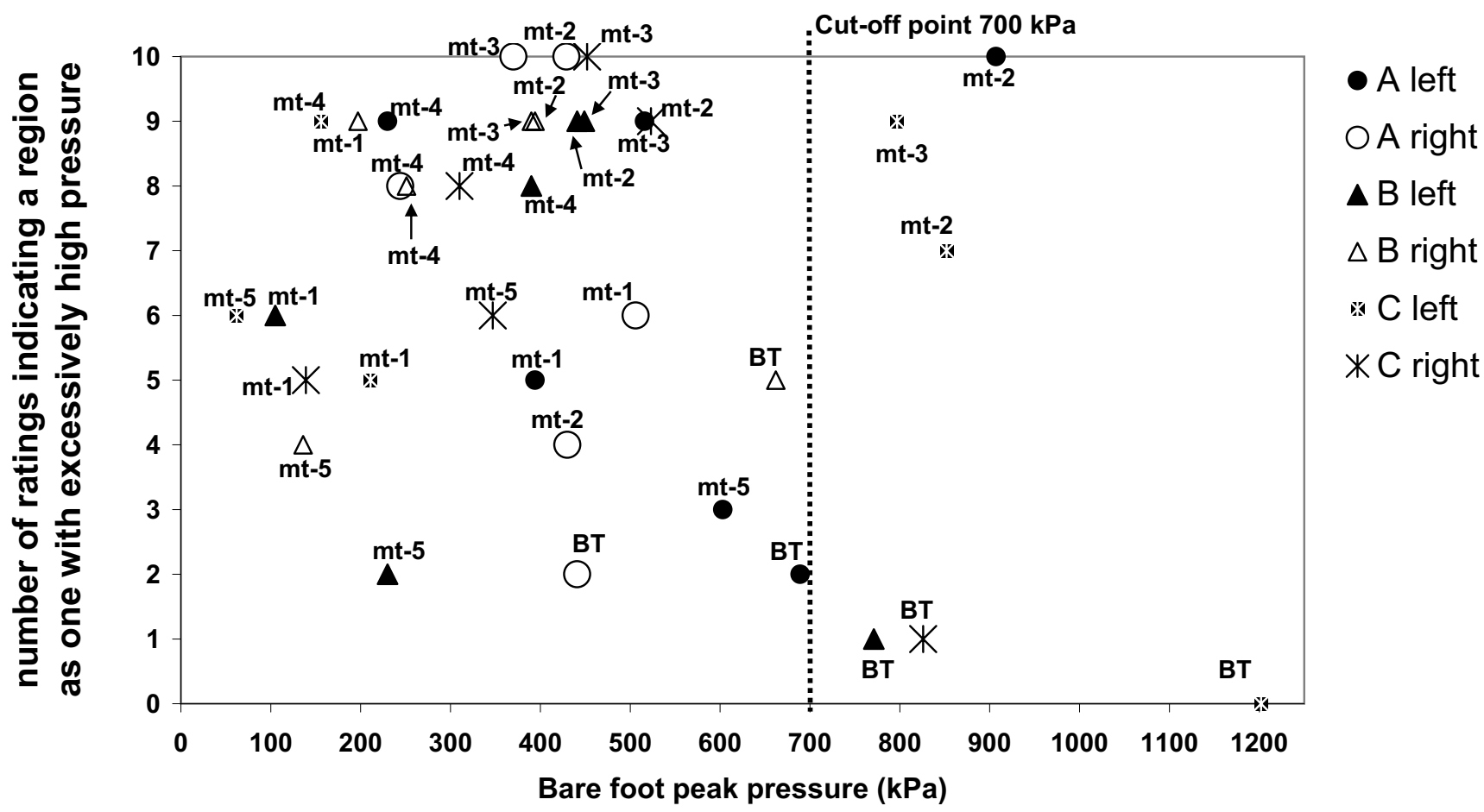

Figure 4

Ratings by orthotists. The distribution of ratings of orthotists who indicated a region as one with excessively high pressure, against the plantar pressure measured with the pressure platform (Gold Standard).

For identification of plantar locations with excessive pressure, most therapists used a footprint device, complementary to their physical examination. These ink print devices are based on 'the Harris and Beath foot printing technique'[42] and consist of a rubber mat with crosswise ridges. It is claimed that from the shade in the ink patterns, a semi-quantitative judgement about plantar pressures can be made[8,42]. Silvino demonstrated that ink print shades only could be distinguished below a pressure of $260 \mathrm{kPa}$, after which full ink blotting occurred and no further differentiation in plantar pressure could be made. Most normal, but especially harmful bare foot plantar pressures in e.g. diabetes and rheumatoid arthritis are much higher than $260 \mathrm{kPa}$. Therefore these ink print devices are no alternative for clinical quantitative plantar pressure measurement. Nonetheless, there was a large variety of methods used by the therapists in taking the footprints e.g. static versus dynamic measurements and semi - versus full weight bearing. These differences have a major influence on pressure patterns $[43,44]$ and this could explain the misidentification of the elevated pressure under the big toe. For example, Cavanagh found that the toes were minimally involved in the static load bearing of the foot: less than $4 \%[27]$. In contrast, the highest

Table 2: 'Gold standard': dynamic bare foot peak pressures for patient A, B and C (kPa)

\begin{tabular}{|c|c|c|c|c|c|c|}
\hline & A left & A right & B left & B right & C left & C right \\
\hline BT & 689 & 441 & 771 & 662 & 1202 & 826 \\
\hline mtl & 394 & 506 & 105 & 197 & 211 & 139 \\
\hline$m t 2$ & 907 & 429 & 441 & 394 & 852 & 523 \\
\hline$m+3$ & 516 & 370 & 449 & 390 & 797 & 452 \\
\hline mt4 & 230 & 244 & 390 & 251 & 156 & 310 \\
\hline mt5 & 603 & 430 & 230 & 136 & 62 & 347 \\
\hline
\end{tabular}

Peak pressures greater than $700 \mathrm{kPa}$ are outlined and bold printed. $\mathrm{BT}=$ big toe, $\mathrm{mt}=$ metatarsal 
Table 3: Observed proportions of elevated plantar pressure according to the GS and to the ratings per discipline

\begin{tabular}{|c|c|c|c|c|c|}
\hline Region & GS & Podiatrist & Pedorthist & Orthotist & Over all disciplines \\
\hline BT & 0.50 & $0.43 \pm 0.50$ & $0.45 \pm 0.50$ & $0.18 \pm 0.39$ & $0.36 * \pm 0.48$ \\
\hline mt-I & 0.00 & $0.20 \pm 0.40$ & $0.37 \pm 0.48$ & $0.60 \pm 0.49$ & $0.39 * * \pm 0.49$ \\
\hline mt-2 & 0.33 & $0.82 \pm 0.39$ & $0.68 \pm 0.47$ & $0.90 \pm 0.30$ & $0.80 * * \pm 0.40$ \\
\hline mt-3 & 0.17 & $0.68 \pm 0.47$ & $0.68 \pm 0.47$ & $0.93 \pm 0.25$ & $0.77 * * \pm 0.44$ \\
\hline mt-4 & 0.00 & $0.42 \pm 0.49$ & $0.58 \pm 0.49$ & $0.83 \pm 0.37$ & $0.6 \mathrm{I} * * \pm 0.49$ \\
\hline mt-5 & 0.00 & $0.38 \pm 0.49$ & $0.40 \pm 0.49$ & $0.42 \pm 0.49$ & $0.40 * * \pm 0.49$ \\
\hline Total & 0.17 & $0.49 \pm 0.50$ & $0.52 * \pm 0.50$ & $0.64 * * \pm 0.48$ & $0.55 * * \pm 0.50$ \\
\hline
\end{tabular}

The proportion of elevated plantar pressure per region according to the GS is determined by the number of regions with observed elevated pressure to all regions for that location: for example, three of the six BT regions (three patients both feet) had elevated pressure i.e. 3:6 $=0.50$. For each region, the ratings per discipline were averaged over both feet of the patients. $\mathrm{BT}=$ big toe, $\mathrm{mt}=$ metatarsal. \pm standard deviation. $*=\mathrm{p}$ value $<.05, * *=p$ value $<.005$

dynamic pressures were found under the metatarsal heads and the big toe $[24,26,28,45]$. Further, it was found that dynamic plantar pressure measurements show high-risk areas in diabetic patients more effectively than static pressure measurements[46].

We have used a cut-off point of $700 \mathrm{kPa}$ for categorising elevated and non-elevated pressures. This arbitrary value is frequently cited as a critical threshold in foot disorders. If we lower the cut-off point to $600 \mathrm{kPa}$, then the GS proportion of elevated pressure in the big toe region would increase. This is illustrated by a shift of the cut-off point from $700 \mathrm{kPa}$ to $600 \mathrm{kPa}$ in figures 2 to 4 . As a result now five $B T$ regions are categorized as elevated, instead of three regions. This leads to a larger underestimation or falsenegative rate: $5: 6=0.83$ versus 0.36 . Not until $500 \mathrm{kPa}$, the results will change in favour of the therapist's ratings for the mt- 1 to $\mathrm{mt}-3$ regions (table 2 and figures 2 to 4 ). Regarding the condition of the patients who participated in this study, we consider a cut-off point $500 \mathrm{kPa}$ as inappropriate. It is still unclear which parameter is most important i.e. the peak pressure or the pressure-time integral, and what can be seen as abnormal values for a specific foot condition[17]. Although, it is widely accepted that 'relatively' elevated foot pressure is an important fac- tor in development of foot complications [16-23]. In the present study three patients with metatarsalgia were evaluated. Studies in patients with other foot pathologies are warranted to put our findings in a wider perspective.

We understand that the method of analysis used in this paper is difficult to comprehend. However, the implication of the results are crystal clear. This study showed that the clinical process for identification of elevated plantar pressure performed by the therapists appears to be insufficient. Aspects of physical examination, clinical reasoning and techniques for elevated plantar pressure screening have to be re-evaluated to improve this clinical process. On the long road ahead, the first step should be an inventory of possible valid methods for plantar pressure screening. Second: a detailed study has to be performed to find a clinical method or a combination of methods and techniques, which can most accurately identify locations with elevated pressure. Third: after validation and standardisation, the best method should be trained and implemented as a standard guideline.

In absence of a useful clinical screening method, quantitative plantar pressure measurement is a valuable alternative for screening. Although the last years, the price of this

Table 4: Estimated within group Method Agreement (ICC)

\begin{tabular}{ccccc}
\hline Region & Podiatrist & Pedorthist & Orthotist & Averaged total \\
\hline BT & 0.77 & 0.77 & 0.86 & 0.80 \\
mt-I & 0.38 & 0.68 & 0.36 & 0.42 \\
mt-2 & 0.82 & 0.78 & 0.87 & 0.82 \\
mt-3 & 0.64 & 0.62 & 0.83 & 0.71 \\
mt-4 & 0.36 & 0.39 & 0.33 & $\mathbf{0 . 3 6}$ \\
mt-5 & 0.56 & 0.33 & 0.39 & $\mathbf{0 . 4 8}$ \\
\hline Averaged total & $\mathbf{0 . 6 7}$ & $\mathbf{0 . 6 5}$ & $\mathbf{0 . 7 6}$ & $\mathbf{0 . 7 0}$
\end{tabular}

Estimated Method Agreement (ICC) between so-called Gold Standard and subjective professional judgment of elevated plantar pressure in regions of both feet, specified for type of therapist and/or foot region. $\mathrm{mt}=$ metatarsal, $\mathrm{BT}=$ big toe 
Table 5: Components of Variance used for calculation of the BT region Method Agreement ICCs in table 4

\begin{tabular}{|c|c|c|c|c|c|c|c|c|c|}
\hline \multicolumn{10}{|c|}{ Part A } \\
\hline & \multicolumn{3}{|c|}{ Podiatrist } & \multicolumn{3}{|c|}{ Pedorthist } & \multicolumn{3}{|c|}{ Orthotist } \\
\hline Source & $\sigma^{2}$ & $\%$ & SE & $\sigma^{2}$ & $\%$ & SE & $\sigma^{2}$ & $\%$ & SE \\
\hline $\mathbf{P}$ & 0.1065 & 25 & 0.078 & 0.0831 & 18 & 0.061 & 0.0458 & 9 & 0.034 \\
\hline$P \times M$ & 0.0630 & 15 & 0.051 & 0.0912 & 20 & 0.070 & 0.1667 & 34 & 0.121 \\
\hline$P \times T$ & 0.0593 & 14 & 0.014 & 0.0407 & 9 & 0.012 & 0.0139 & 3 & 0.006 \\
\hline S within P & 0.0435 & 10 & 0.038 & 0.0377 & 8 & 0.027 & 0.0188 & 4 & 0.010 \\
\hline $\begin{array}{c}M \times S \\
\text { within P }\end{array}$ & 0.0519 & 12 & 0.034 & 0.0815 & 18 & 0.053 & 0.1611 & 33 & 0.104 \\
\hline $\begin{array}{c}\mathbf{T} \times \mathbf{S} \\
\text { within P }\end{array}$ & 0.0074 & 2 & 0.002 & 0.0134 & 3 & 0.004 & 0.0153 & 3 & 0.004 \\
\hline Total & 0.3315 & & & 0.3477 & & & 0.4215 & & \\
\hline \multicolumn{10}{|c|}{ Part B } \\
\hline & \multicolumn{3}{|c|}{ Podiatrist } & \multicolumn{3}{|c|}{ Pedorthist } & \multicolumn{3}{|c|}{ Orthotist } \\
\hline & $\sigma^{2}$ & $\%$ & SE & $\sigma^{2}$ & $\%$ & SE & $\sigma^{2}$ & $\%$ & SE \\
\hline$P \times M \times T$ & 0.0870 & 20 & 0.028 & 0.0755 & 17 & 0.024 & 0.0375 & 8 & 0.012 \\
\hline $\begin{array}{l}M \times T \times S \\
\text { within } P e\end{array}$ & 0.0148 & 3 & 0.004 & 0.0269 & 6 & 0.007 & 0.0306 & 6 & 0.008 \\
\hline Total & 0.1019 & & & 0.1023 & & & $0.068 I$ & & \\
\hline
\end{tabular}

Total percentage is the summation of part $\mathrm{A}$ and $\mathrm{B} . \sigma^{2}=$ estimated variance component, $\mathbf{P}=$ patient, $\mathbf{M}=\operatorname{method}, \mathbf{G}=\operatorname{group}, \mathbf{T}=$ therapist, $\mathbf{S}=$ side, and e designates the ultimate 'error' $\sigma^{2}$ component in the model specified. $\mathrm{SE}=$ standard error, $\mathrm{BT}=$ big toe

equipment has decreased and easy-to-use soft- and hardware has become available, plantar pressure measurement is not a standard facility in foot care practices. The financial investment for purchase and exploit of this equipment seems relatively small compared to the health benefits.

\section{Conclusion}

Exact identification of locations with elevated plantar pressure through clinical evaluation is difficult: pressures in the big toe region tend to be underestimated and are likely to be overestimated in the metatarsal regions. Apart from being neglected, inaccurate identification of elevated pressure could result in mistreatment. There was a poor agreement between the therapists studied. There appears to be no relevant difference in the proficiency to distin- guish regions with elevated plantar pressure between podiatrists, pedorthists and orthotists. The process of clinical plantar pressure screening has to be re-evaluated. The results of this study point towards the merit of quantitative plantar pressure measurement for clinical practice.

\section{Competing interests}

The author(s) declare that they have no competing interests.

\section{Authors' contributions}

All authors designed the study. NG collected and prepared the data. NG, PL and FN analyzed the data. All authors interpreted and discussed the data. NG, PL, FN and GW drafted the manuscript. NA, FN and PL revised the manu-

Table 6: Estimated mutual Agreement (ICC)

\begin{tabular}{cccc}
\hline Region & Podiatrist-Pedorthist & Podiatrist-Orthotist \\
BT & 0.53 & 0.59 & 0.37 \\
mt-I & 0.70 & 0.17 & 0.32 \\
mt-2 & 0.44 & 0.64 & 0.01 \\
mt-3 & 0.06 & 0.48 & 0.00 \\
mt-4 & 0.36 & 0.01 & 0.30 \\
mt-5 & 0.66 & 0.000 \\
\hline
\end{tabular}

Estimated mutual Agreement (ICC) of plantar peak pressure of one therapist out of 10 between two out of three disciplines (podiatrists, pedorthists and orthotists) and regions of the forefoot averaged over three patients (both feet). Results are between 0.000 (absolutely no mutual agreement) and 1.000 perfect mutual agreement). 
script. All authors read and approved the final manuscript.

\section{Appendix}

formula's where: $\sigma^{2}=$ estimated variance component, $P=$ \# patient, $\mathrm{M}=$ method, $\mathrm{G}=$ group, $\mathrm{T}=$ \# therapist, $\mathrm{R}=$ region, $S=$ side, and e designates the ultimate 'error' $\sigma^{2}$ component in the model specified.

Table 4

Group- and Region specific formula for Method Agreement - upper left part of Table 4.

Model: per Region and Group: Therapist $\times$ Method $\times$ (Side within Patient).

$$
\mathrm{A} 1=\frac{\sigma_{\mathrm{P}}^{2}+\sigma_{\mathrm{PM}}^{2}+\sigma_{\mathrm{PT}}^{2}+\sigma_{\mathrm{S}: \mathrm{P}}^{2}+\sigma_{\mathrm{MS}: \mathrm{P}}^{2}+\sigma_{\mathrm{TS}: \mathrm{P}}^{2}}{\text { same as numerator }+\sigma_{\mathrm{PMT}}^{2}+\sigma_{\mathrm{MTS}: \mathrm{P}, \mathrm{e}}^{2}}
$$

Region-specific formula for Method Agreement - right totals column in Table 4.

Model per Region: Method $\times$ (Therapist within Group) $\times$ (Side within Patient).

$\mathrm{A} 2=\frac{\sigma_{\mathrm{P}}^{2}+\sigma_{\mathrm{PM}}^{2}+\sigma_{\mathrm{PG}}^{2}+\sigma_{\mathrm{PGM}}^{2}+\sigma_{\mathrm{GS}: \mathrm{P}}^{2}+\sigma_{\mathrm{PT}: \mathrm{G}}^{2}+\sigma_{\mathrm{TS}: \mathrm{PG}}^{2}+\sigma_{\mathrm{SM}: \mathrm{P}}^{2}+\sigma_{\mathrm{GSM}: \mathrm{P}}^{2}}{\text { same as numerator }+\sigma_{\mathrm{PMT}: \mathrm{G}}^{2}+\sigma_{\mathrm{TSM}: \mathrm{PG},}^{2} \mathrm{e}}$

Group-specific formula for Method Agreement-bottom totals row in Table 4.

Model per Group: Therapist $\times$ Method $\times[($ Region $\times$ Side $)$ within Patient]

$\mathrm{A} 3=\frac{\sigma_{\mathrm{P}}^{2}+\sigma_{\mathrm{PM}}^{2}+\sigma_{\mathrm{PT}}^{2}+\sigma_{\mathrm{R}: \mathrm{P}}^{2}+\sigma_{\mathrm{S}: \mathrm{P}}^{2}+\sigma_{\text {TR:P }}^{2}+\sigma_{\text {TS:P }}^{2}+\sigma_{\mathrm{RS}: \mathrm{P}}^{2}+\sigma_{\mathrm{RM}: \mathrm{P}}^{2}+\sigma_{\mathrm{SM}: \mathrm{P}}^{2}+\sigma_{\text {SM:P }}^{2}+\sigma_{\text {TRS:P }}^{2}+\sigma_{\mathrm{RSM}: \mathrm{P}}^{2}}{\text { same as numerator }+\sigma_{\mathrm{PMT}}^{2}+\sigma_{\text {TRM:P }}^{2}+\sigma_{\text {TSM:P }}^{2}+\sigma_{\text {TRSM:P }}^{2} \mathrm{e}}$

Overall formula for Method Agreement - bottom right, general total in Table 4.

Model Method $\times($ Therapist within Group $) \times[($ Region $\times$ Side) within Patient]

$$
\mathrm{A} 4=\frac{\sigma_{\mathrm{SR}: \mathrm{P}}^{2}+\sigma_{\mathrm{MGS}: \mathrm{P}}^{2}+\sigma_{\mathrm{MGR}: \mathrm{P}}^{2}+\sigma_{\mathrm{MSR}: \mathrm{P}}^{2}+\sigma_{\mathrm{GSR}: \mathrm{P}}^{2}+\sigma_{\mathrm{MGSR}: \mathrm{P}}^{2}+\sigma_{\mathrm{PT}: \mathrm{G}}^{2}+\sigma_{\mathrm{ST}: \mathrm{PG}}^{2}+\sigma_{\mathrm{RT}: \mathrm{PG}}^{2}+\sigma_{\mathrm{RST}: \mathrm{PG}}^{2}}{\text { same as numerator }+\sigma_{\mathrm{PMT}: \mathrm{G}}^{2}+\sigma_{\mathrm{MTS}}^{2} \mathrm{PG}+\sigma_{\mathrm{MTRR}: \mathrm{PG}}^{2}+\sigma_{\mathrm{MTSR}: \mathrm{PG},}^{2} \mathrm{e}}
$$

Formula for agreement among therapists

Model Therapist $\times$ (Side within Patient)

$$
\mathrm{A} 5=\frac{\sigma_{\mathrm{P}}^{2}+\sigma_{\mathrm{S}: \mathrm{P}}^{2}}{\sigma_{\mathrm{P}}^{2}+\sigma_{\mathrm{S}: \mathrm{P}}^{2}+\sigma_{\mathrm{PT}}^{2}+\sigma_{\mathrm{TS}: \mathrm{P}, \mathrm{e}}^{2}}
$$

Table 6
Two Groups- and Region specific formula for mutual Agreement: upper part of Table 6.

Model per Region and for two Groups: (Therapist within Group $) \times($ Side within Patient $)$

$$
\mathrm{B} 1=\frac{\sigma_{\mathrm{P}}^{2}+\sigma_{\mathrm{PG}}^{2}+\sigma_{\mathrm{S}: \mathrm{P}}^{2}+\sigma_{\mathrm{GS}: \mathrm{P}}^{2}}{\text { same as numerator }+\sigma_{\mathrm{PT}: \mathrm{G}}^{2}+\sigma_{\mathrm{TS}: \mathrm{PG}, \mathrm{e}}^{2}}
$$

Two Groups specific formula for mutual Agreement: bottom totals row in Table 6 .

Model for two Groups: (Therapist within Group) $x$ [(Region $\times$ Side $)$ within Patient]

$$
\mathrm{B} 2=\frac{\sigma_{\mathrm{P}}^{2}+\sigma_{\mathrm{PG}}^{2}+\sigma_{\mathrm{S}: \mathrm{P}}^{2}+\sigma_{\mathrm{R}: \mathrm{P}}^{2}+\sigma_{\mathrm{GS}: \mathrm{P}}^{2}+\sigma_{\mathrm{GR}: \mathrm{P}}^{2}+\sigma_{\mathrm{GSR}: \mathrm{P}}^{2}+\sigma_{\mathrm{SR}: \mathrm{P}}^{2}}{\text { same as numerator }+\sigma_{\mathrm{PT}}^{2}+\sigma_{\mathrm{ST}: \mathrm{PG}}^{2}+\sigma_{\mathrm{RT}: \mathrm{PG}}^{2}+\sigma_{\mathrm{RST}: \mathrm{PG}, \mathrm{e}}^{2}}
$$

\section{Acknowledgements}

This study was supported by The Netherlands Organisation for Health Research and Development (ZonMw) and the Dutch Diabetes Research Foundation. We thank patients and therapists who participated in this study.

\section{References}

I. Mueller MJ: Application of plantar pressure assessment in footwear and insert design. J Orthop Sports Phys Ther 1999, 29:747-755.

2. Grifka JK: Shoes and insoles for patients with rheumatoid foot disease. Clin Orthop 1997:18-25.

3. Armstrong DG, Peters EJ, Athanasiou KA, Lavery LA: Is there a critical level of plantar foot pressure to identify patients at risk for neuropathic foot ulceration? J Foot Ankle Surg 1998, 37:303-307.

4. Cavanagh PR, Ulbrecht JS: Biomechanics of the foot in diabetes mellitus. In The Diabetic foot 4th edition. Edited by: Levin ME, O'Neal LW and Bowker JH. St. Louis, MO, Mosby; 1994:199-232.

5. Orlin MN, McPoil TG: Plantar pressure assessment. Phys Ther 2000, 80:399-409.

6. Woodburn J, Helliwell PS: Foot problems in rheumatology [editorial]. Br J Rheumatol 1997, 36:932-934.

7. Connor H: Prevention of Diabetic Foot Problems. In The Foot in Diabetes 2 nd edition. Edited by: Boulton AJ, Connor $\mathrm{H}$ and Cavanagh PR. Chichester, West Sussex, John Wiley \& Sons Ltd; 1994:57-67.

8. Silvino N, Evanski PM, Waugh TR: The Harris and Beath footprinting mat: diagnostic validity and clinical use. Clin Orthop 1980:265-269.

9. Hughes J, Kriss S, Klenerman L: A clinician's view of foot pressure: a comparison of three different methods of measurement. Foot Ankle 1987, 7:277-284.

10. Mathieson I, Upton D, Birchenough A: Comparison of footprint parameters calculated from static and dynamic footprints. The Foot 1999, 9:145-199.

II. Kannus VP: Evaluation of abnormal biomechanics of the foot and ankle in athletes. Br J Sports Med 1992, 26:83-89.

12. Welton EA: The Harris and Beath footprint: interpretation and clinical value. Foot Ankle 1992, 13:462-468.

13. Kruizinga CP, Boonstra A, Groothoff JW, Elzinga A, Goeken NLH: Characteristics of patients supplied with foot orthoses from orthopaedic workshops in The Netherlands. The Foot 2003, 13:39-45.

14. Zuijderduin WM, Dekker J: Diagnoses and interventions in podiatry. Disability and Rehabilitation 1996, 18:27-34.

15. Guldemond NA, Leffers P, Schaper NC, Sanders AP, Nieman FH, Walenkamp GH: Comparison of foot orthoses made by podiatrists, pedorthists and orthotists regarding plantar pressure 
reduction in The Netherlands. BMC Musculoskelet Disord 2005, 6:6I.

16. Frykberg RG, Lavery LA, Pham H, Harvey C, Harkless L, Veves A Role of neuropathy and high foot pressures in diabetic foot ulceration. Diabetes Care 1998, 21:1714-1719.

17. Cavanagh PR, Ulbrecht JS, Caputo GM: New developments in the biomechanics of the diabetic foot. Diabetes Metab Res Rev 2000, 16 Suppl I:S6-S10.

18. Lavery LA, Armstrong DG, Wunderlich RP, Tredwell J, Boulton AJ: Predictive value of foot pressure assessment as part of a population-based diabetes disease management program. Diabetes Care 2003, 26: 1069-1073.

19. Peters EJ, Lavery LA: Effectiveness of the diabetic foot risk classification system of the International Working Group on the Diabetic Foot. Diabetes Care 200I, 24: I442-I 447.

20. Malay DS: Mechanically induced metatarsalgia. Gait Posture 1996, 4:198-199.

21. Otter SJ, Bowen CJ, Young AK: Forefoot plantar pressures in rheumatoid arthritis. J Am Podiatr Med Assoc 2004, 94:255-260.

22. van der Leeden M, Steultjens M, Dekker JH, Prins AP, Dekker J: Forefoot joint damage, pain and disability in rheumatoid arthritis patients with foot complaints: the role of plantar pressure and gait characteristics. Rheumatology (Oxford) 2006, 45:465-469.

23. Hsi WL, Kang JH, Lee XX: Optimum position of metatarsal pad in metatarsalgia for pressure relief. Am J Phys Med Rehabil 2005, 84:5I4-520.

24. Bryant AR, Tinley P, Singer KP: Normal values of plantar pressure measurements determined using the EMED-SF system. J Am Podiatr Med Assoc 2000, 90:295-299.

25. Luger EJ, Nissan M, Karpf A, Steinberg EL, Dekel S: Patterns of weight distribution under the metatarsal heads. J Bone Joint Surg $\mathrm{Br}$ 1999, $8 \mathrm{I}$ :p 199-202.

26. Hayafune N, Hayafune $Y$, Jacob HAC: Pressure and force distribution characteristics under the normal foot during the pushoff phase in gait. The Foot 1999, 9:88-92.

27. Cavanagh PR, Rodgers MM, liboshi A: Pressure distribution under symptom-free feet during barefoot standing. Foot Ankle 1987, 7:262-276

28. Bennett PJ, Duplock LR: Pressure distribution beneath the human foot. J Am Podiatr Med Assoc 1993, 83:674-287.

29. Hennig EM, Staats A, Rosenbaum D: Plantar pressure distribution patterns of young school children in comparison to adults. Foot Ankle Int 1994, I 5:35-40.

30. Bus SA, de Lange A: A comparison of the I-step, 2-step, and 3step protocols for obtaining barefoot plantar pressure data in the diabetic neuropathic foot. Clin Biomech (Bristol, Avon) 2005, 20:892-899.

31. van der Leeden M, Dekker JH, Siemonsma PC, Lek-Westerhof SS, Steultjens MP: Reproducibility of plantar pressure measurements in patients with chronic arthritis: a comparison of one-step, two-step, and three-step protocols and an estimate of the number of measurements required. Foot Ankle Int 2004, 25:739-744

32. Wearing SC, Urry S, Smeathers JE, Battistutta D: A comparison of gait initiation and termination methods for obtaining plantar foot pressures. Gait Posture 1999, 10:255-263.

33. McPoil TG, Cornwall MW, Dupuis L, Cornwell M: Variability of plantar pressure data. A comparison of the two-step and midgait methods. J Am Podiatr Med Assoc 1999, 89:495-50I.

34. Quaney B, Meyer K, Cornwall MW, McPoil TG: A comparison of the dynamic pedobarograph and EMED systems for measuring dynamic foot pressures. Foot Ankle Int 1995, 16:562-566.

35. Weijers RE, Walenkamp GHIM, Mameren van H, Kessels AG: The relationship of the position of the metatarsal heads and peak plantar pressure. Foot and Ankle Int 2003, 24:349-353.

36. Shavelson RJ, Webb NM: Generalizability Theory: a primer. In Measurement methods for the social sciences series I Volume XIII, I37 p. Newbury Park, CA, Sage Publications; 1991.

37. Crick JE, Brennan RL: GENOVA: a GENeral purpose analysis of VAriance system. version 2.2. edition. 1984

38. Streiner DL, Norman GR: Health Measurement Scales: a practical guide to their development and use. In Oxford medical publications 2nd edition. Oxford, Oxford University Press; 1995:231 p.

39. Cohen J: A coefficient for agreement for nominal scales. Educational and psychological measurement:a quarterly journal devoted to the development and application of measures of individual differences 1960, 20:37-46.

40. Portney LG, Watkins MP: Foundations of clinical research: applications to practice. Norwalk, Conn., Appleton \& Lange; 1993:722 P.

4I. Bus SA, Ulbrecht JS, Cavanagh PR: Pressure relief and load redistribution by custom-made insoles in diabetic patients with neuropathy and foot deformity. Clin Biomech (Bristol, Avon) 2004, 19:629-638.

42. Harris RI, Beath T: Army foot survey: an investication of foot alignments in Canadian soldiers. In National Research Council of Canada Ottawa, ; 1947.

43. Diebschlag W: [Pressure distribution on the sole of the human foot while standing and walking, barefoot and with shoes]. $Z$ Orthop 1982, I 20:p8|4-20.

44. Betts RP, Franks Cl, Duckworth T, Burke J: Static and dynamic foot-pressure measurements in clinical orthopaedics. Med Biol Eng Comput 1980, I 8:674-684.

45. Duckworth T, Boulton AJ, Betts RP, Franks Cl, Ward JD: Plantar pressure measurements and the prevention of ulceration in the diabetic foot. J Bone Joint Surg [Br] 1985, 67:79-85.

46. Alexander IJ, Chao EY, Johnson KA: The assessment of dynamic foot-to-ground contact forces and plantar pressure distribution: a review of the evolution of current techniques and clinical applications. Foot Ankle 1990, I I:I52-167.

\section{Pre-publication history}

The pre-publication history for this paper can be accessed here:

http://www.biomedcentral.com/1471-2474/7/93/prepub
Publish with Biomed Central and every scientist can read your work free of charge

"BioMed Central will be the most significant development for disseminating the results of biomedical research in our lifetime. "

Sir Paul Nurse, Cancer Research UK

Your research papers will be:

- available free of charge to the entire biomedical community

- peer reviewed and published immediately upon acceptance

- cited in PubMed and archived on PubMed Central

- yours - you keep the copyright
BioMedcentral 